\title{
Cerebral Fornix
}

National Cancer Institute

\section{Source}

National Cancer Institute. Cerebral Fornix. NCI Thesaurus. Code C32289.

The C-shaped bundle of axons in the midline of the brain which originate in both hemispheres of the hippocampus and project to the contralateral hippocampus and septum, mammillary body, and the anterior nucleus of the thalamus. 